\title{
Inconsistencies in the pozzolanic strength activity index (SAI) for silica fume according to EN and ASTM
}

\author{
Rein Terje Thorstensen $\cdot$ Per Fidjestol
}

Received: 2 August 2013/Accepted: 21 October 2014/Published online: 11 November 2014

(C) The Author(s) 2014. This article is published with open access at Springerlink.com

\begin{abstract}
New supplementary cementitious materials claimed to possess pozzolan properties emerge frequently. This development is driven both by economic and environmental pressures. Properties of new materials are compared with those of materials already well known, such as silica fume. Several test methods are standardized for making such comparisons, regulated by both European (EN) and American (ASTM) standards. Standardization indicates that procedures are secured to make comparisons valid and informative. In this article the sensitivity of accepted variations within each of the standard procedures are investigated to determine if the results are influenced by such variations. Various methods for testing pozzolanic properties are briefly discussed. Experimental work was carried out in compliance with the standard methods for testing silica fume, according to both EN and ASTM. Seventy two mixes are made and tested in the experimental series, combining two
\end{abstract}

The Board of Editors was informed of the death of the coauthor of this article, Professor Per Fidjestøl, while the manuscript was still under review.

R. T. Thorstensen ( $\square)$

University of Agder, Jon Lilletunsvei 9, 4879 Grimstad, Norway

e-mail: rein.t.thorstensen@uia.no

P. Fidjestol

Elkem AS Silicon Materials and University of Agder,

Kristiansand S, Norway standard procedures, two types of sand, three cements and four flow agents (SP). The results show that determined values are highly influenced by variations accepted to be made within the standard procedures. Possible reasons for these variations are analyzed. Conclusions are made that even when complying with the standards, the results are heavily manipulable (intended or unintended). Also a shortcoming in EN regarding new materials, is detected. Suggestions are made on additional information required to be given together with the results when reporting pozzolanic properties according to standards in order to make results informative and reproducible. A limitation in EN towards testing nano-sized silica materials is detected. An adjustment is suggested, to make EN applicable correspondingly to ASTM, also for these materials.

Keywords Pozzolan - Supplementary cementitious materials (SCM) - Standard (EN13263 and ASTM C1240) - Strength activity index (SAI) - Microsilica · Nano-sized silica

\section{Introduction}

Pozzolan is defined as "a siliceous and aluminous material which, in itself, possesses little or no cementitious value but which will, in finely divided form in the presence of moisture, react chemically with 
calcium hydroxide at ordinary temperature to form compounds possessing cementitious properties" [1].

Remains of concrete in constructions built 9,000 years ago is found in archaeological excavations in Yiftah El east of Jerusalem [12]. The use of pozzolans as part of the binder in concrete dates back to antiquity. "Pozzolans" are named after the Romans' use of ash from the volcano Pozzolana, but the practice is far older. It is argued that pozzolanic concrete was used on Kameiros Rhodos in 500 BC in buildings still standing 2,500 years later [4], and in Mesoamerica in the period 1100-850 BC [14].

Pozzolans might be natural occurring or industrial by-products. Variations in both mineralogical composition and particle characteristics heavily influence the efficiency of their pozzolanic properties. Some pozzolans are able to enhance the quality of hardened concrete, including durability, compressive strength, shrinkage, creep and permeability, and to reduce cracking [11]. Some are also capable of making fresh concrete more cohesive and thus less prone to segregation [8].

The technology for replacing clinker in cement (supplementary cementitious materials-SCM) and for achieving improved quality and durability of concrete by the use of pozzolans, is rapidly being developed. Exploitation of natural resources and industrial by-products as pozzolans, is driven by both economic and environmental incentives. The concrete industry is widely accepted to be responsible for 5-7\% of global $\mathrm{CO}_{2}$ emissions, with approximately $90 \%$ attributable to production of Portland cement. Materials from new sources are frequently claimed to have pozzolanic capacity. Effects of these new materials as SCM and for enhancement of concrete quality are compared to that of materials already well known.

Several test methods are standardized for making such comparisons. Though test methods are standardized, not all constituents included in the test procedures are precisely specified. One investigation comparing three alternative methods of determining pozzolanic activity executed on four materials expected to be pozzolanic, demonstrated that two of the methods showed good correlation, while the third method did not correlate at all [5]. This indicates that comparative results can be influenced by choice of the test method.

The objective of this research is to investigate whether and how the results from standard tests vary, depending on how tests are performed. We focus on the well-recognized method of testing strength activity index (SAI), which is standardized both in EN- and ASTM-standards. There are different standards for different categories of pozzolans. In this investigation, the standards for silica fume are followed (EN13263 [7] and ASTM C1240 [2]). The paper is organized as follows: in Sect. 2 methods and materials are clarified, in Sect. 3 the results are presented and discussed, and in Sect. 4 conclusions are drawn and some suggestions for future work are made.

\section{Materials and methods}

\subsection{Pozzolanic reaction}

Portland cement (PC) has several clinker compounds, each contributing differently to the properties of the fresh concrete and hardening process. When $\mathrm{PC}$ reacts with water, calcium silicate hydrate $(\mathrm{C}-\mathrm{S}-\mathrm{H})$ is formed, constituting the main part of the binder. In addition, calcium hydroxide $\mathrm{Ca}(\mathrm{OH})_{2}$ is formed. Calcium hydroxide does not possess any binding properties, but buffers $\mathrm{pH}$ in the pore water to approximately 12.4 (in addition, alkalis add $\mathrm{pH}$ to the characteristic level above 13). High $\mathrm{pH}$ is an advantage in structural use of concrete, since reinforcement steel is protected with respect to corrosion at these levels.

Pozzolans are characterized by the ability to react with calcium hydroxide, resulting in more $\mathrm{C}-\mathrm{S}-\mathrm{H}$ binder. Pozzolanic reactivity depends heavily on the size of the material particles. Some materials are known to possess pozzolanic properties only when particles are less than $45 \mu \mathrm{m}$ in diameter, and to have reactivity proportional to the amount of particles less than $10 \mu \mathrm{m}$ (e.g. for fly ash in [11]. Silica fume particles is often in the range $d_{50}=0.15 \mu \mathrm{m}$.

Standard PC particles are typically sized in the range $0.5-60 \mu \mathrm{m}$, in average about $10-100$ times that of silica fume. If effectively dispersed, the silica fume particles fill the cavities between the cement and aggregate particles. Even if not reacting chemically, the introduction of these small particles will improve compressive strength and durability of concrete through more dense particle packing of aggregate [9]. In the hardening process, the cement will first react, forming $\mathrm{C}-\mathrm{S}-\mathrm{H}$ and a surplus of calcium 
hydroxide. Only then can the silica fume react, creating more $\mathrm{C}-\mathrm{S}-\mathrm{H}$ in the cavities between what was created by the cement. Concrete made with silica fume is therefore often less porous, having higher compressive strength and better durability. However, the hardening process of many silica fumes is slow compared to that of Portland clinker.

Both the compressive strength and the reduced level of $\mathrm{Ca}(\mathrm{OH})_{2}$ are being used as indicators for pozzolanic activity, through alternative methods.

\subsection{Alternative test methods}

Test methods for detection of pozzolan activity are divided into two main categories: direct methods measuring consumption of $\mathrm{Ca}(\mathrm{OH})_{2}$, and indirect methods measuring relative compressive strength of test specimens-Strength activity index (SAI). No method is considered to be superior to the others. However, there seem to be a tendency that scientific work on certain pozzolans primarily relate to certain methods. Both ASTM and EN standards for manufacturing of silica fume, specify methods based on SAI. This investigation focuses on SAI. Knowledge of other test methods is still interesting as a mean of verification.

\subsection{Direct methods}

Both the "Frattini test" [6] and the simplified "Saturated lime test" (SL) [10] are commonly used. In the Frattini test, the anticipated pozzolanic material is added to a solution containing PC (CEM I). In the SL test, the solution contains saturated lime water, rather than PC. For both tests, consumption of $\mathrm{Ca}(\mathrm{OH})_{2}$ is measured, using X-ray diffraction (XRD), thermogravimetric analysis (TGA) or chemical titration.

A comparison between Frattini and SL methods performed at Imperial College in London, concluded that results from the two direct methods do not at all correlate [5]. Explanations are sought both in experimental work, and in shortcomings of methods. It is argued that the differences can be explained by shortcomings in the described methods.

Results from the Frattini test do correlate rather well with results from the indirect SAI test $\left(R^{2}=0.86\right)$, that was also performed. The SAI test (explained below) was executed according to EN (BS 3892-pulverized fuel-ash [3], later replaced by EN450). Water was used as flow agent to ensure that the required flow-criterion was achieved. However, the large variation of water content (and hence of water-binder-ratio (W/B) as PC content was kept constant), undoubtedly affect the resulting compressive strength. As relative variations in compressive strength is the indicator for pozzolanic activity, Donatello et al. [5] advice using super-plasticizer (SP) rather than water, for achieving the flow desired. This is standard in EN450 and both standards in this investigation.

\subsection{Indirect method—-strength activity index} (SAI)

SAI is in principle determined by molding two sets of test specimens according to a standard recipe: one with $100 \%$ PC (reference), and another where a standardized part of the PC is replaced by corresponding mass of the pozzolan to be tested. After curing, both sets of specimens are tested for

Table 1 Comparing procedures in standards for silica fume

\begin{tabular}{|c|c|c|}
\hline Property & EN13263 & ASTM C1240 \\
\hline Reference mix & $\begin{array}{l}\text { Test cement: } 450 \mathrm{~g} \\
\text { Standard sand: } 1,350 \mathrm{~g} \\
\text { Distilled Water: } 225 \mathrm{~g}\end{array}$ & $\begin{array}{l}\text { Test cement: } 500 \mathrm{~g} \\
\text { Standard sand: } 1,375 \mathrm{~g} \\
\text { Distilled water: } 242 \mathrm{~g} \\
\text { Flow agent (SP): X g }\end{array}$ \\
\hline Pozzolan (by replacement) & $45 \mathrm{~g}$ & $50 \mathrm{~g}$ \\
\hline $\begin{array}{l}\text { Flow agent (SP) } \\
\text { (Flow measured with } \\
\text { special equipment) }\end{array}$ & $\begin{array}{l}\text { Super-plasticizer conforming to EN-934-2. As } \\
\text { much SP as required to obtain the flow of the } \\
\text { reference. }( \pm 5 \mathrm{~mm})\end{array}$ & $\begin{array}{l}\text { Dry high-range water reducer, meeting specification } \\
\text { C494 Type F. As much SP as required to obtain a } \\
\text { flow of } 100-115 \% \text { (sum of four measurements, } \\
\text { done with special caliper) }\end{array}$ \\
\hline Curing (after $24 \mathrm{~h}$ in mold) & Submerged in water for 27 days at $20 \pm 1{ }^{\circ} \mathrm{C}$ & In airtight glass containers at $65 \pm 2{ }^{\circ} \mathrm{C}$ for 6 days \\
\hline
\end{tabular}


Table 2 Overview of materials used

\begin{tabular}{llll}
\hline Cements & Sands & Pozzolans & SP \\
\hline Norcem Anlegg & ASTM C778-02 C109 & Microwhite PW(Perlite) & Modified polycarboxylate \\
Norcem Industri & BS EN 196-1 Standard & Microsilica 940U & Sulfonated melamine \\
Blue Circle & - & Submicron 995 (nano-silica) & Modified lignosulfonate \\
- & - & - & Polycarboxylate derivatives \\
\hline
\end{tabular}

compressive strength. The effect of the pozzolanic material is expressed as strength activity index $\left.\left.\mathrm{SAI}=\sigma_{(\text {pozzolan mix }}\right) / \sigma_{(\text {reference })}\right)$ EN13263 and [2] concerns silica fume. Both standards works with SAI like the principle described above, but vary in details of the procedures as described in Table 1.

Both standards specify details of materials and procedures for mixing and for filling of molds, and for the shape of test specimens. Both standards were followed, with some minor adjustments. One of which is that specimens cured at high temperature (ASTM) were submerged in water, due to earlier experiences with severe variations in results when curing over water in airtight containers, as described in the standard. Explanations for the variations were sought in uncontrolled drying of specimens, probably due to insufficient airtightness. Repeated tests with specimens submerged in water during curing at high temperature have eliminated these variations. Other adjustments to standards were related to choice of materials, and are mentioned later.
Pozzolanic reactions are known to be temperature sensitive. Curing regimes are stated in each standard. All experiments were performed within a concentrated period of time, in a laboratory with near constant temperature of $20{ }^{\circ} \mathrm{C}$. All constituents were stored in the lab for several days prior to mixing, to achieve constant temperature. This includes also the deionized water used in all mixes, and curing of mortar specimens in the moulds for the first $24 \mathrm{~h}$.

\subsection{Materials used}

A general overview of all materials used is given in Table 2. Both standards have cement requirements that become increasingly difficult to meet because of changes in cement production. For the present investigation several cements were therefore tested Table 3 . Two types of standard sands were used, characterized in Fig. 1. Specifications of the four tested types of SPs are given in Table 4, and of the three pozzolans in Table 5 .

Table 3 Cement specifications

\begin{tabular}{|c|c|c|c|c|}
\hline Property & Units & $\begin{array}{l}\text { Norcem Anlegg } \\
\text { EN197-1 CEM I 52,5 N }\end{array}$ & $\begin{array}{l}\text { Norcem Industri } \\
\text { EN197-1 CEMI 42,5 RR }\end{array}$ & $\begin{array}{l}\text { Blue Circle } \\
\text { EN197-1 CEMII/A-LL 42,5 }\end{array}$ \\
\hline Surface area & $\mathrm{m}^{2} / \mathrm{kg}$ & 360 & 550 & $360-470$ \\
\hline App particle density & $\mathrm{kg} / \mathrm{m}^{3}$ & 3,160 & 3,140 & $3,080-3,180$ \\
\hline Comp strength 2 days & $\mathrm{N} / \mathrm{mm}^{2}$ & 30 & 42 & $21-30$ \\
\hline Comp strength 7 days & $\mathrm{N} / \mathrm{mm}^{2}$ & 46 & 49 & $36-50$ \\
\hline Comp strength 28 days & $\mathrm{N} / \mathrm{mm}^{2}$ & 60 & 57 & $45-65$ \\
\hline Sulfate $\mathrm{SO}_{3}$ & $\%$ & $3.0-4.0$ & $3.0-4.0$ & $2.5-3.5$ \\
\hline Chloride & $\%$ & $<0.08$ & $<0.08$ & $<0.06$ \\
\hline Clinker & $\%$ & 96 & 96 & $\begin{array}{l}80-95 \\
\left(40-60 \% \mathrm{C}_{2} \mathrm{~S}, 6-25 \% \mathrm{C}_{2} \mathrm{~S}\right)\end{array}$ \\
\hline $\mathrm{C}_{3} \mathrm{~A}$ & $\%$ & 7 & 7 & $6-12$ \\
\hline LOI & $\%$ & 2.5 & 2.5 & - \\
\hline Setting time initial & $\min$ & 120 & 100 & $95-150$ \\
\hline Alkali & $\%$ & 0.6 & 1.3 & $0.35-0.65$ \\
\hline
\end{tabular}




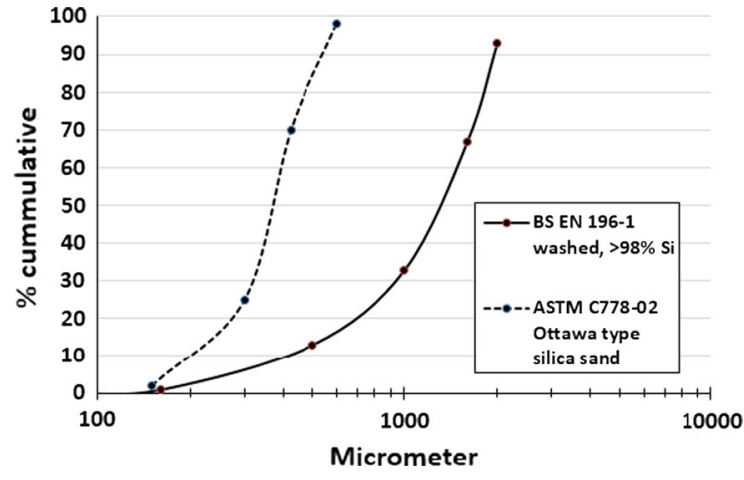

Fig. 1 Sand specifications

\section{Results and discussion}

\subsection{Effects in SAI by varying type of SP}

Neither ASTM nor EN specifies details of SP to be used, except ASTM requiring SP to be dry Type F (high range water reducing agent, according to ASTM C494). Two of the SPs used in this investigation were dispersed in water. When using these, the water content in SP were subtracted from the water in the mix specification. The lack of detailed SP specification might give the impression that SAI should not be influenced by choice of SP. The results show that when keeping all other variables than type of SP constant, SAI vary severely (up to $44 \%$ ) and apparently unpredictably (Fig. 2).

The resulting SAI varied $34 \%$ when varying the type of SP, for one given combination of cement and pozzolan when measured according to EN (Fig. 3). No single result of compressive strength varied by more than $4 \%$ from corresponding within test average. This small within test variation is well within the limit of $10 \%$ stated in the standard, and does not constitute a possible explanation for the big observed variations in SAI.

A possible explanation might be that the amount of air entrained in the test specimens varies with the type of SP, which is likely to be caused by different consistency of the mortar. Both EN and ASTM use flow as measure of consistency, and as seen in Fig. 3, flow does vary. Both standards specify routines for

Table 4 SP specifications

\begin{tabular}{|c|c|c|c|c|}
\hline Chemical group & $\begin{array}{l}\text { Sulfonated } \\
\text { melamine }\end{array}$ & $\begin{array}{l}\text { Polycarboxylate } \\
\text { derivatives }\end{array}$ & $\begin{array}{l}\text { Modified } \\
\text { polycarboxylate }\end{array}$ & $\begin{array}{l}\text { Modified } \\
\text { lignosulfonate }\end{array}$ \\
\hline Form & Powder & Fluid & Fluid & Powder \\
\hline Colour & White & Light yellow & Light grey & Brown \\
\hline $\mathrm{pH}$ & $\begin{array}{l}9.0-11.4 \text { at } 20{ }^{\circ} \mathrm{C} \\
\text { and } 20 \% \text { solution }\end{array}$ & 6.5 & 5.5 & $6.9-8.3$ \\
\hline Density & $500-800 \mathrm{~kg} / \mathrm{m}^{3}$ & $1.03 \mathrm{~kg} / \mathrm{l}$ & $1.04 \mathrm{~kg} / \mathrm{l}$ & $600 \mathrm{~kg} / \mathrm{m}^{3}$ \\
\hline Chloride & - & $<0.01 \%$ of weight & $<0.01 \%$ of weight & $<0.1 \%$ of weight \\
\hline Alkali & - & $<1.5 \%$ of weight & $<0.5 \%$ of weight & Max $10 \%$, normally 5-10\% \\
\hline Rec dosage & $0.2-2.0 \%$ of binder & $0.5-2.0 \%$ of binder & $0.2-2.0 \%$ of binder & $0.2-2.0 \%$ of binder \\
\hline Shelf life & 2 years & 1 year & 9 months & Several months \\
\hline Dry content & - & $14 \%$ of mass & $18 \%$ of mass & - \\
\hline
\end{tabular}

Table 5 Pozzolan specifications

\begin{tabular}{llll}
\hline Property & Microwhite PW & Microsilica $940 \mathrm{U}$ & Submicron 995 \\
\hline Active constituents & $>98 \%$ perlite (approx $71 \% \mathrm{SiO}_{2}$ & $>90 \% \mathrm{SiO}_{2}$ & $>99.5 \% \mathrm{SiO}_{2}$ \\
& $\left.+13 \% \mathrm{Al}_{2} \mathrm{O}_{3}\right)$ & & $\mathrm{d}_{100}=0.4 \mu \mathrm{m}$ \\
Particle size & $\mathrm{d}_{90}=15 \mu \mathrm{m}$ & $\mathrm{d}_{90}=0.42 \mu \mathrm{m}$ & $90-110 \mathrm{~kg} / \mathrm{m}^{3}$ \\
Bulk density & $350-600 \mathrm{~kg} / \mathrm{m}^{3}$ & $200-350 \mathrm{~kg} / \mathrm{m}^{3}$ & 2.2 \\
Specific gravity & $2.2-2.4$ & 2.2 & $50 \mathrm{~m}^{2} / \mathrm{g}$ \\
Surface area & $<20 \mathrm{~m}^{2} / \mathrm{g}$ & $15-30 \mathrm{~m}^{2} / \mathrm{g}$ & 0 \\
Crystallinity & $<1.5 \%$ & 0 & \\
\hline
\end{tabular}


Fig. 2 Span in SAI

$\left(\mathrm{SAI}_{\text {highest }}-\mathrm{SAI}_{\text {lowest }}\right)$ due to variations in type of SP, for all combination of cement and pozzolan (according to EN). All results based on average of three parallel specimens
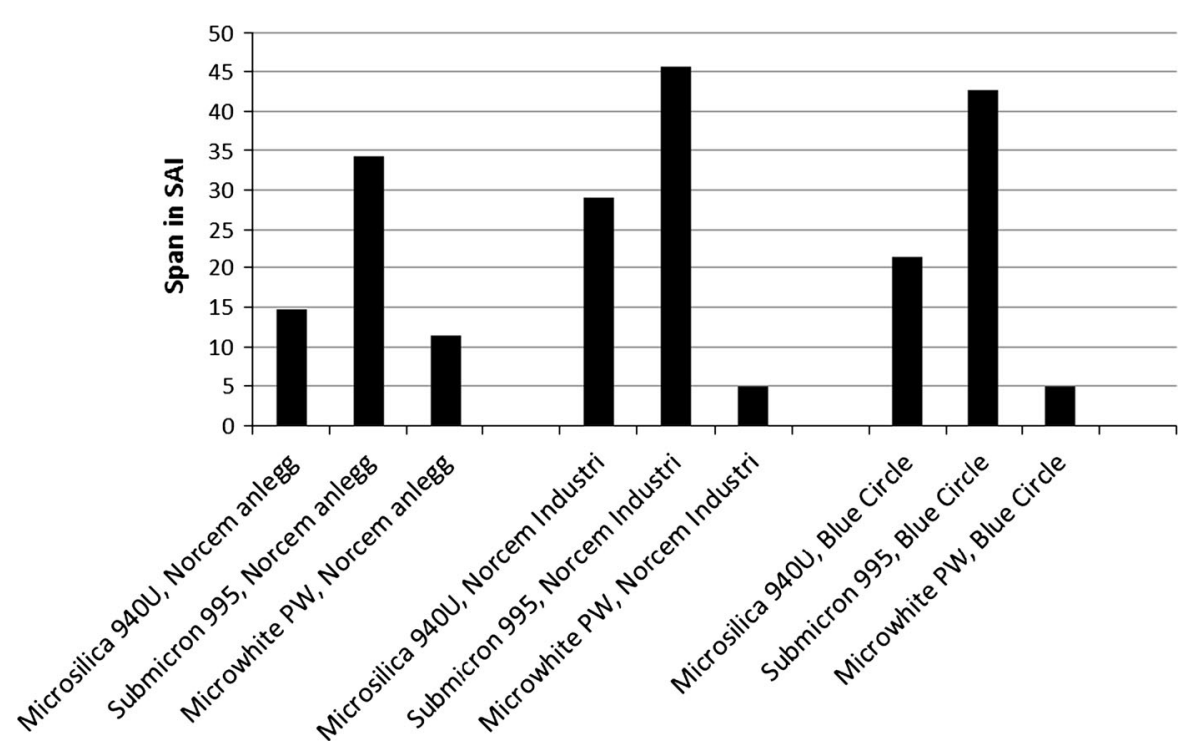

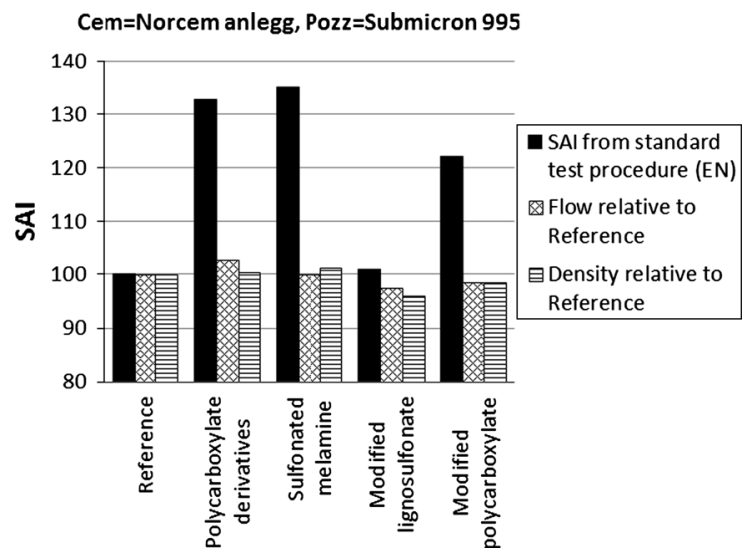

Fig. 3 Typical effect on SAI, flow and density when varying type of SP, for one combination of cement and pozzolan (according to EN)

filling the molds, thus individual processing to reduce air entrainment should not be performed. To investigate the possible influence of unintentional air entrained by the SP, the density of each specimen was calculated. The results show that the amount of entrained air does vary between mixes with different SPs. The lignosulfonate-based SP induces more air entrained than the polycarboxylate-based and the melamine-based SPs. This is in accordance with theory (e.g. [15], pp 30-31).

Rixom also suggests a method to estimate the reduction in 28 days compressive strength due to increased air entrainment in concrete [15], pp 135136). An adaption of this method is used to recalculate

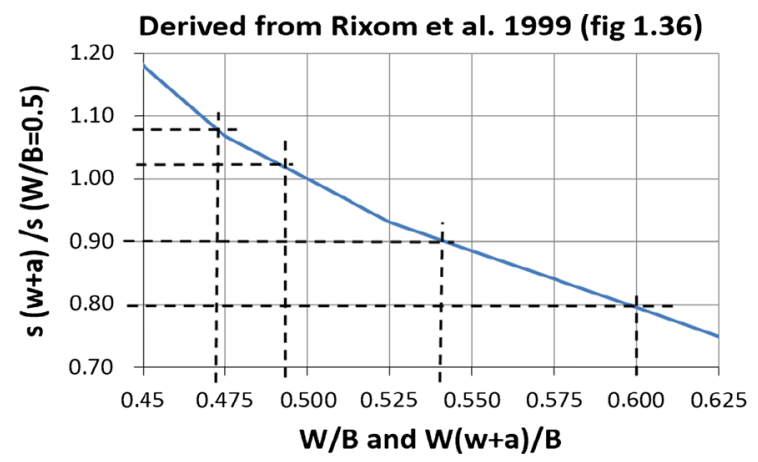

Fig. 4 Correcting compressive strength(s) with respect to variations in air entrainment

compressive strength to air entrainment level corresponding to that in the Reference mix. According to this method, the additional air entrained is considered as an equivalent volume of water, and added to the water already in the mix. This new water-and-air/ binder ratio $\left(W_{(w+a)} / B\right)$ is used to estimate an adjusted 28-day compressive strength from standard curves. The test specimens are made of mortar, while Rixom's method was developed for concrete. When using the adapted method, it is anticipated that normal concrete is used with approximately $400 \mathrm{~kg}$ binder $\mathrm{m}^{-3}$. The additional air content in the mixes containing SP based on sulfonated melamine and lignosulfonate, is equivalent to varying the water to binder ratio $(W / B)$ in the span $\left.W_{(w+a)} / B=0.48-W_{(w+a)}\right) / B=0.60$, respectively, compared to the reference mix with $W / B=$ 0.50 . The adjusted $W / B$-ratio is used to determine the 
$\sigma_{(w+a)} / \sigma_{(W / B=0,5)}$ ratio (Fig. 4), leading to the adjusted compressive strength.

Using this method is of course an approximation, since it was developed for concrete and this investigation concerns mortar with $d_{\max }=2 \mathrm{~mm}$. However, no method known to the authors is exact in correcting compressive strength for variations in entrained air. This is an attempt to separate the effect of the air entrained from other possible effects, based on theory from scientific work on SPs. When applying the calculated correction factor to the SAI-results originally calculated, variations in SAI are substantially reduced. The particularly "discrediting" results from use of lignosulfonate-based SP were rejected (Fig. 5 left part).

Corresponding reversed proportionality between SAI and entrained air is also observed for other combinations of cement and pozzolans. Once again, correcting SAI for differences in air entrainment heavily reduces the differences in SAI due to type of SP (Fig. 5 right part).

Still after correction for entrained air, SAI varies significantly as function of type of SP for some of the combinations of materials. However, it is not known whether these variations are due to different chemical reactions or due to insufficiency in the method used for correcting for variations in content of entrained air. The different types of SPs react inconsequently with the mixes containing different silica fumes, when it comes to ability to induce air entrainment (Fig. 6). The use of SP based on sulfonated melamine contributed to inducing the least air entrainment in the mix containing



Fig. 6 Levels of air entrainment relative to that of reference mix, as function of SP

Submicron 995, but this mix has the highest air entrainment when using SP based on modified lignosulfonate. Depending on the SP used, it might be concluded that Submicron 995 has both the highest and the lowest SAI of the three pozzolansif not taking entrained air into consideration.

Whether the aim is to perform a scientific measure of the pozzolanic properties of a substance, or for commercial purposes by a producer: determining SAI without simultaneously considering differences in the level of entrained air and stating the type of SP used, appears insufficient.

\subsection{Effects on SAI by varying type of cement}

Both ASTM C1240 and EN 13263 specify some characteristics of cements, still allowing substantial variations. Specifications are not the same for the two standards. Results show that altering the type of cement induces significant changes in SAI (Fig. 7) for
Fig. 5 SAI corrected for variations in air entrainment relative to that of the reference mix, for two combinations of cement and pozzolan

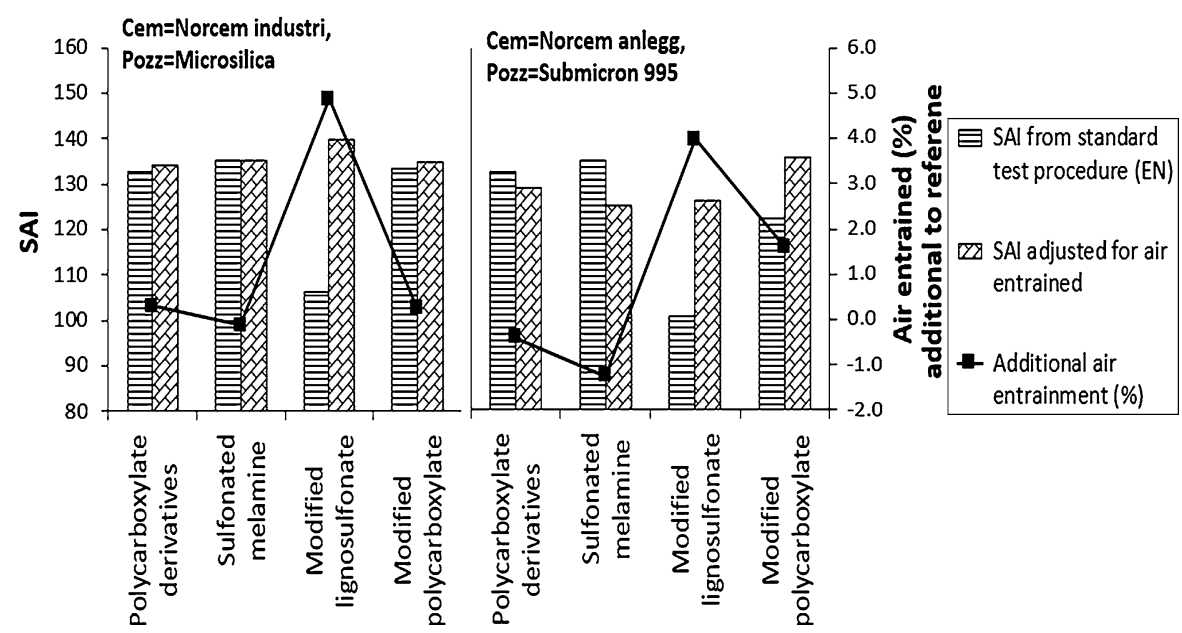






Fig. 7 Variations in SAI due to type of cement, for all combinations of silica fume and SP (according to EN)

all combinations of pozzolan and SP. Once again, questions are whether these variations can be explained by differences in air entrainment, or if pozzolanic reactions differ.

To reduce the disturbing effects described above, the aim of the following discussion is to identify the SP which results in the lowest additional air entrainment in these tests. From Fig. 8 it is found that SP based on sulfonated melamine is the best to evaluate influence on SAI when varying type of cement, since both the overall level and internal differences in additional air entrainment are minimized.

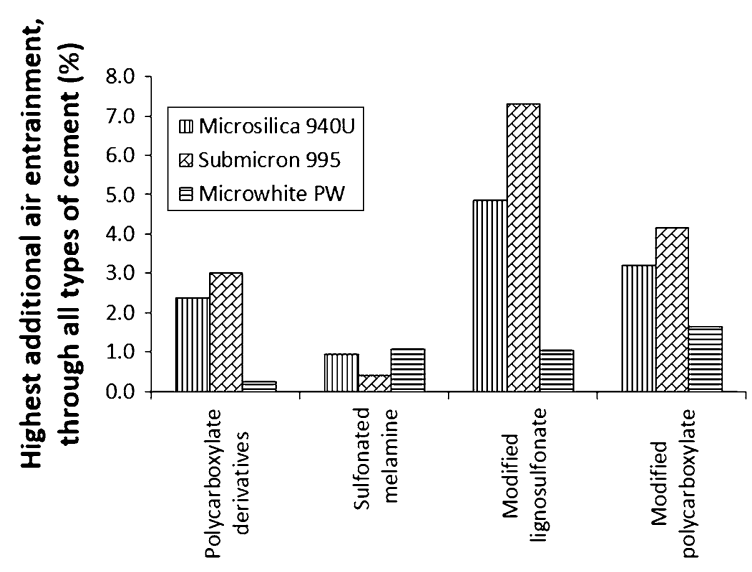

Fig. 8 Highest additional air entrainment (relative to reference mix) through all types of cement, sorted by SP
When evaluating variations of type of cement while keeping SP constant (sulfonated melamine), it is shown that SAI vary strongly for all three types of pozzolans (Fig. 9 left part). Once again applying the adapted Rixom method for adjusting for differences in air entrainment, this time does not contribute to reducing the differences in SAI (Fig. 9 right part). Thus, changing type of cement does influence the strength developed from pozzolanic reaction present, and consequently the SAI determined.

One explanation for the higher SAI-values with Norcem Industri than with Norcem Anlegg cement might seem obvious: Norcem Industri has a specific surface area of $550 \mathrm{~m}^{2} / \mathrm{kg}$, compared to 360 in Norcem Anlegg. The substantially higher surface area allows Norcem Industri to hydrate quicker, speeding up the availability of calcium hydroxide needed for the pozzolan reactions. However, whilst this accelerated effect of the finely ground cement is relevant up to about 7 days, the SAI is measured at 28 days. The chemical composition of these two cements are very similar. The total amount of released calcium hydroxide could therefore be expected to be similar at 28 days.

One could expect to find the results from the Blue Circle cement somewhere in between those from the two Norcem cements, as the specific surface area is equal to or a little higher than Norcem Anlegg cement. Additionally, taking into account that this is a CEM II 

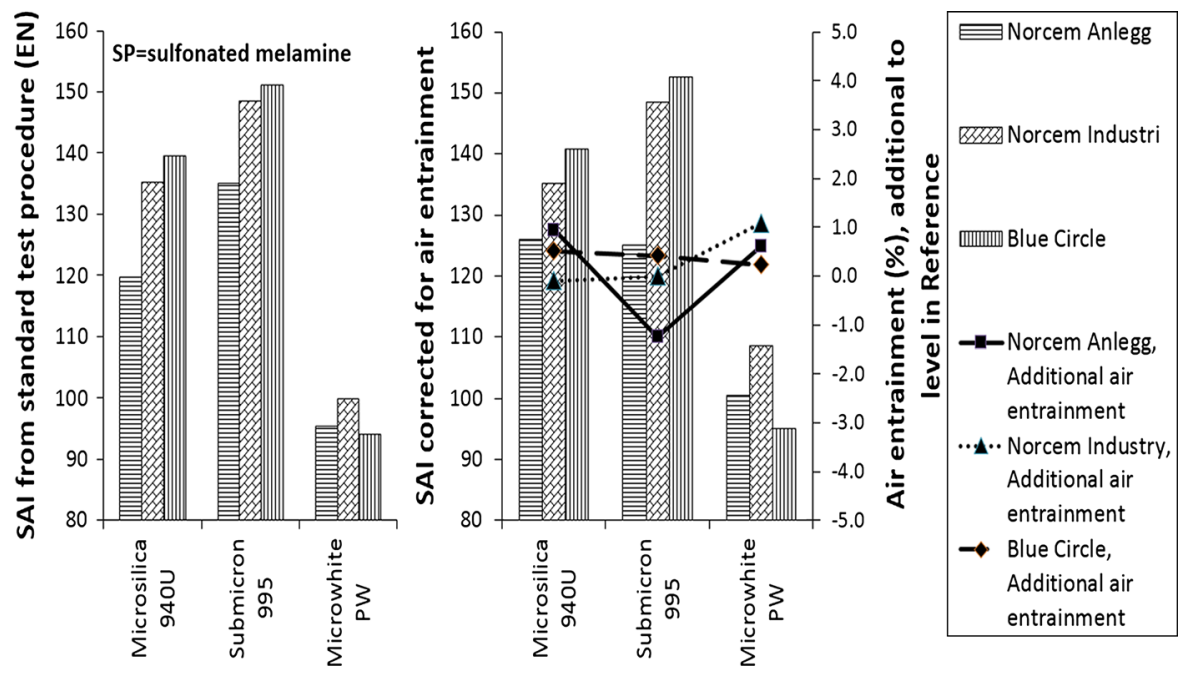

Fig. 9 Variations in SAI due to altering type of cement (according to EN), corrected for variations in air entrainment

with substantial content of limestone-powder (6-20\%), it has lower content of ordinary Portland clinker (OPC). Blended cements with high content of limestone-powder are found to give lower levels of calcium hydroxide during the first 28 days of curing than CEM I [16]. The net effect of these two conditions, was expected to reduce SAI. However, the opposite is observed; SAI is higher for Microsilica 940U and Submicron 955, combined with the blended cement, than when using either types of CEM I. Only Microwhite PW reacts consistently with this line of reasoning.

Blended limestone-Portland-cements have been shown to accelerate the hydration of calcium silicate components of cement [13]. Even though the hydration products of blended cements are quite similar to those resulting from OPC, the production process comprising sequences of blending and grinding, is known to be able to affect both hydration rate and stoichiometry [16]. Thus, lack of uniformity from the production process, and also additional chemical reactions between the supplementary cementitious materials in the blended cement, probably explains the observed variations in SAI when using CEM II. Thus, the results from this investigation support the standards' claim to use CEM I only.

Submicron 995 seems to gain most amongst the three pozzolans, from the use of fine ground cement. Submicron 995 is a nano-sized material, having nearly double the surface area per weight unit, than Microsilica. This increases the speed with which it can react, when calcium hydroxide is available. A synergetic effect is that the $\mathrm{SiO}_{2}$-content of Submicron 995 is close to $10 \%$ higher than in Microsilica 940U. Microwhite PW, having the lowest specific surface area and lowest content of $\mathrm{SiO}_{2}$ (also when adding $\mathrm{Al}_{2} \mathrm{O}_{3}$ ), also gain least from the use of Industri cement with finer particles.

\subsection{Effects on SAI by choice of standard}

Not all materials used in the evaluation are in compliance with the standards. The aim of exceeding the standards is to evaluate limitations and potentials. Valid combinations of standards and materials are as shown in Table 6.

Using cement Norcem Anlegg, which is the only one of the three cements satisfying both standards, yields severe differences in SAI between the two standard procedures, for all pozzolans (Fig. 10 left part). But SAI is based on internally compared results, and neither of the set of values can be said to be more correct than the other.

Having the lowest $\mathrm{SiO}_{2}$-content and the lowest specific surface area, the pozzolan Microwhite PW is expected to show significantly lower SAI than the other two materials. Both standard procedures are found to be consistent with this expectation. SAI for Microwhite PW varies from 100 to $120 \%$ between the standards, and are in both cases significantly lower than corresponding values for the other silicas. 
Table 6 Materials compliance with standards (single or double strikethrough visualize lack of compliance with one or both standards)

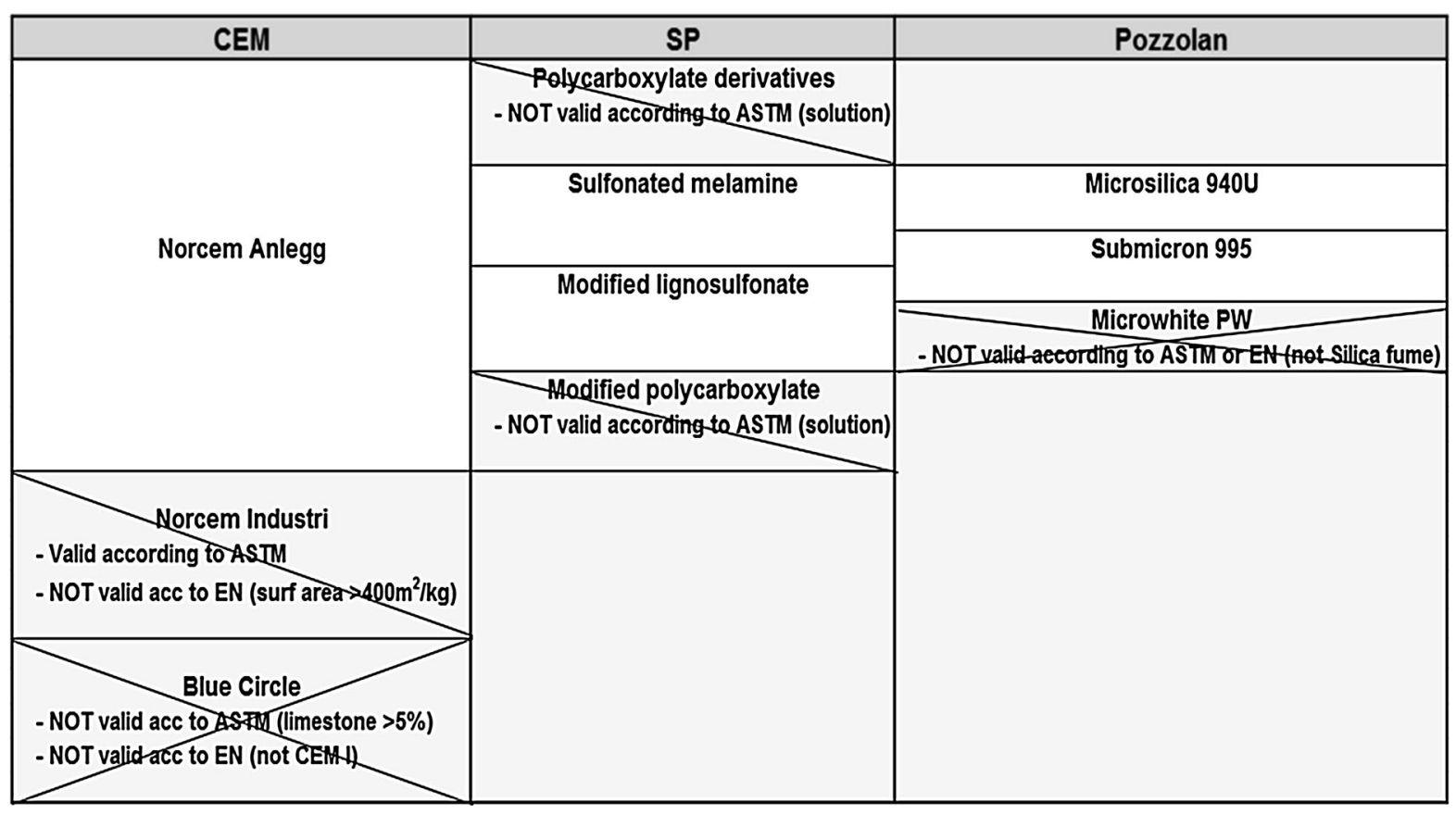



Fig. 10 Variations in SAI due to altering standards

Both the higher content of $\mathrm{SiO}_{2}$ and the higher specific surface area, leads to the expectation that Submicron 995 should show significantly higher SAI than Microsilica 940U. However, the opposite is found according to both standards, when using Norcem Anlegg (Fig. 10 left part).

When used together with the finer grounded Norcem Industri, Submicron 995 achieved significantly higher SAI than Microsilica 940U-in accordance with expectations (Fig. 10 right part). Corresponding results were determined by both standards, even if Norcem Industry is not in compliance with EN.

\section{Conclusions}

SAI values are always relative, as the determination is based on strength ratios. As a minimum, results of test specimens from a mix where cement is partly substituted by a substance expected to possess pozzolanic properties, is compared to those of specimens from a reference mix without cement substitution. Often the pozzolanic properties of several substances are tested and compared sequentially in the same study. Therefore, the following issues should be considered: 


\section{On flow agent (SP)}

A. The level of air entrainment is shown to be significantly affected by the specific combination of SP and pozzolan used in the mix. The use of different SPs can change both absolute level and relative level of SAI between pozzolans in the same test series. The use of SP is necessary for achieving sufficient flow according to the procedures in both the EN and ASTM standards. However, it is not clear whether the demonstrated differences in SAI are caused solely by different levels of air entrainment, or if the chemical mechanisms in which the pozzolans react as binders are also involved. A dedicated method to distinguish effects of air entrainment from actual differences in SAI is needed.

B. Comparable SAI test results should not be evaluated without simultaneously considering the corresponding comparative level of air entrainment, even internally in one study where only one type of SP is used. The type of SP and relative level of air entrainment (compared to reference mix) should always be stated together with SAI, when results are reported.

\section{On cement}

C. Use of different cements influence SAI after 28 days of curing, even when all cements are CEM I. Use of CEM I with different finenesses does not seem to be a problem when determining SAI for micro-sized silica fume particles, but detailed information on cement properties should always be stated as part of the SAI-information.

D. This study indicates that specimens from mortar containing nano-sized silica fume particles gains more strength when combined with a finely ground cement, than mortar containing microsized silica fume particles. Hence, it is suggested that full utilization of nano-sized silica fume particles requires sufficient fineness of the cement.

E. Use of blended cements is not shown to give unreasonable results, but variations in results may not be easily predicted or explained. The standards' claim to use CEM I only, is supported.

\section{On standards (EN13263 vs ASTM C1240)}

F. Levels of SAI determined for micro-size silica fumes vary between the standards, but relative levels between different silica fumes are consistent. Based on the variations in the level of SAI determined; reporting of SAI-values should always include information on what standard was being followed.

G. Limitations on fineness of cement seem to make the EN method unsuitable for determining the SAI of nano-sized silica fume particles. Use of finer cement than currently accepted in EN are likely to give results corresponding to those from ASTM. However, until EN accepts the use of cements with finer particles, only ASTM seems applicable for determining SAI for nano-sized silica fume particles.

Acknowledgments The author would like to thank Bachelor students Ole Johnny Kleven, Henning Rasmussen, Tov Ramberg and Andreas Jahren for all the conscientiously committed work at the lab. Senior engineer Paul Svennevig for clever advices and management of the students. Prof Bernt Lie for being challenging and very supportive. Aust-Agder fylkeskommune «Grønt Stipend» and Regionalt forskningsfond Agder «Proj 203810» for sponsoring.

Open Access This article is distributed under the terms of the Creative Commons Attribution License which permits any use, distribution, and reproduction in any medium, provided the original author(s) and the source are credited.

\section{References}

1. ASTM C125 (2007) Standard terminology relating to concrete and concrete aggregates. ASTM International, West Conshohocken

2. ASTM C1240 (2005) Standard specification for silica fume used in cementitious mixtures. ASTM International, West Conshohocken

3. British standard (BS) 3892 (1997) Pulverised fuel-ash. Part 1: specification for pulverized fuel ash for use with Portland cement. British Standards Institution, London

4. Davidovits J (1987) Ancient and modern concretes: What is the real difference? Concr Int 9:23-28

5. Donatello S, Tyrer M, Cheeseman CR (2010) Comparison of test methods to assess pozzolanic activity. Cement Concr Compos 32:121-127. doi:10.1016/j.cemconcomp.2009.10. 008 
6. BS-EN 196-5 (2011) Methods of testing cement-part 5: pozzolanicity test for pozzolanic cement. British Standards Institution, United Kingdom

7. BS EN 13263-1 (2005) Silica fume for concrete-part 1: definitions, requirements and conformity criteria. British Standards Institution, United Kingdom

8. Holland TC (2005)Silica Fume User's Manual. FHWA-IF05-016

9. Fidjestol P, Thorsteinsen RT, Svennevig P (2012) Making UHPC with local materials-the way forward. In: Proceedings of HiPerMat 2012, 3rd international symposium on UHPC and Nanotechnology for high performance construction materials, Kassel University Press GmbH ISBN 978-3-86219-264-9, pp 207-214

10. de Luxán MP, Madruga F, Saavedra J (1989) Rapid evaluation of pozzolanic activity of natural products by conductivity measurement. Cem Concr Res 19(1):63-68

11. Malhotra VM, Mehta PK (2005) High performance, high volume fly ash concrete: materials, mixture proportioning, properties, construction practice and case histories, supplementary cementing materials for sustainable development, Ottawa, Canada

12. Malinowski R, Garfinkel Y (1991) Prehistory of concrete. Concr Int 13:62-68

13. Ramachandran VS, Zhang $\mathrm{C}$ (1986) Influence of $\mathrm{CaCO}_{3}$ on hydration and microstructural characteristics of tricalcium silicate. II Cemento 83(3):129-152

14. Rivera Villarreal R, Krayer S (1996) Ancient structural concrete in Mesoamerica. Concr Int 18:67-70

15. Rixom R, Mailvaganam N (1999) Chemical admixtures for concrete. Taylor \& Francis Group, Routledge, pp 30-31 ISBN 0-419-22520-X

16. Voglis N, Kakali G, Chaniotakis E, Tsivilis S (2005) Portland-limestone cements. Their properties and hydration compared to those of other composite cements. Cement Concr Compos 27:191-196. doi:10.1016/j.cemconcomp. 2004.02.006 